\title{
Lokalizacja tomografem ultradźwiękowym miejsca na granicy ośrodków o różnej gęstości w elemencie betonowym
}

\author{
Localization of the place on the border between mediums \\ of different density using ultrasonic tomography
}

\section{Streszczenie}

W artykule przedstawiono zastosowanie tomografu ultradźwiękowego do lokalizacji miejsca na granicy ośrodków o różnej gęstości w elemencie betonowym dostępnym z jednej strony. Dla czytelności artykułu przedstawiono najważniejsze zagadnienia związane z propagacją fal mechanicznych. Wykonano obliczenia numeryczne MES w programie ABAQUS dla zamodelowanego elementu betonowego. Na podstawie tych obliczeń pokazano możliwość lokalizacji miejsca na granicy ośrodków o różnej gęstości umieszczonych w elemencie betonowym dostępnym z jednej strony. Następnie wykonano badania nieniszczące $z$ wykorzystaniem tomografu ultradźwiękowego, na podstawie których zlokalizowano miejsce na granicy ośrodków o rożnej gęstości i tym samym potwierdzono możliwość wykonania takiej lokalizacji przy pomocy tomografu ultradźwiękowego oraz prawidłowość opracowanego modelu numerycznego.

Słowa kluczowe: beton, badania nieniszczące, tomograf ultradźwiękowy

\begin{abstract}
The article describes the use of an ultrasound scanner to locate the place on the border between mediums of different density in the concrete element. For clarity, the article presents the most important issues related to the propagation of mechanical waves. The first step FEM numerical calculations in ABAQUS program were performed. The possibility to locate points from the boundaries of different density disposed in the concrete element are shown on the basis of these calculations. Next, a non-destructive testing with use of ultrasonic tomography, which were used to locate the boundaries of different density and thus confirmed the possibility to find such a location using ultrasonic tomography and the correctness of the numerical model developed.
\end{abstract}

Keywords: concrete, nondestructive evaluation, ultrasonic tomography

\section{Wstęp}

W praktyce inżynierskiej często mamy do czynienia z koniecznością określenia geometrii istniejących konstrukcji budowlanych i lokalizacji umieszczonych w nich mediów. Zadanie to jest utrudnione, jeżeli dostęp do konstrukcji jest jednostronny i nie ma dokumentacji budowlanej, a w wielu przypadkach tak właśnie jest. Przykładem może być potrzeba określenia położenia przewodów PCW zabetonowanych w płycie lub posadzce betonowej. Można wówczas wykonać odkrywki, ale wiąże się to z kosztami wynikającymi z prac odkrywkowych, naprawczych i wyłączenia pomieszczenia z użytkowania na czas robót budowlanych. Przydatne do tego celu mogą być jednak metody nieniszczące, w szczegól-

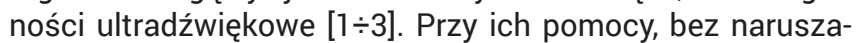
nia struktury betonu, możemy określić położenie przewodów instalacji sanitarnych, wodociągowych, kabli sprężających itp. zabetonowanych w płycie lub posadzce betonowej. W przypadku niedrożności takiego przewodu, tak jak pokazano to na rysunku 1, nieniszczące określenie położenia miejsca na granicy ośrodków o różnej gęstości może również znacznie ułatwić rozwiązanie problemu. W większości ultradźwiękowych metod nieniszczących wykorzystywane są fale podłużne $[1 \div 3]$. Najnowsze z metod pozwalają na wykorzystanie fali poprzecznej, która w porównaniu do fali podłużnej charakteryzuje się mniejszym rozpraszaniem podczas pro-

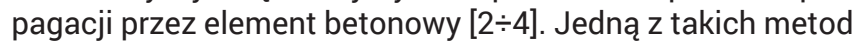
jest metoda tomografii ultradźwiękowej.

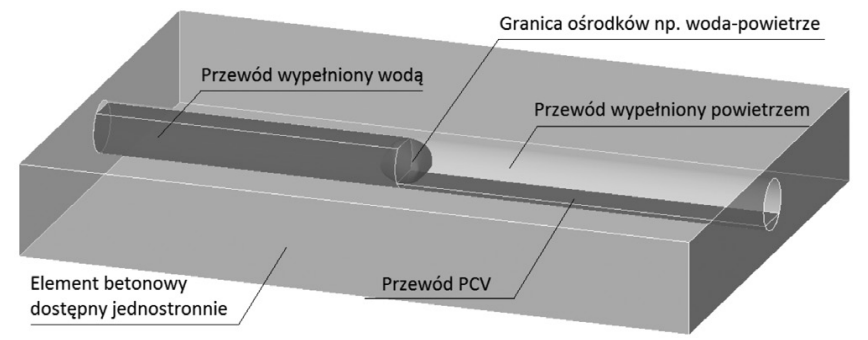

Rys. 1. Ilustracja niedrożności - miejsca na granicy ośrodków o różnej gęstości znajdującego się w elemencie betonowym dostępnym jednostronnie

Fig. 1. Illustration of obstruction - a place on the border of different density mediums located in the concrete element

Dr hab. inż. Krzysztof Schabowicz, mgr inż. Łukasz Radzik - Politechnika Wrocławska, Wydział Budownictwa Lądowego i Wodnego. 
W artykule przedstawiono możliwość lokalizacji miejsca na granicy ośrodków o różnej gęstości, umieszczonych w elemencie betonowym dostępnym jednostronnie za pomocą tomografu ultradźwiękowego wykorzystującego fale poprzeczne.

\section{Sposób propagacji fal ultradźwiękowych w ośrodkach stałych}

W celu lokalizacji miejsca na granicy ośrodków o różnej gęstości zaproponowano zastosowanie fal ultradźwiękowych. Teoria propagacji tych fal w ośrodkach stałych została już wielokrotnie opisana $\mathrm{m}$. in. w $[5,6]$. Warto jedynie podać, dla czytelności artykułu, że falą ultradźwiękową nazywamy zaburzenie ośrodka rozprzestrzeniające się poprzez drgania cząsteczek $[5,6]$. Rozróżnia się trzy rodzaje fal mechanicznych: falę podłużną (rys. 2a), falę poprzeczną (rys. 2b) oraz falę powierzchniową (rys. 2c). a)

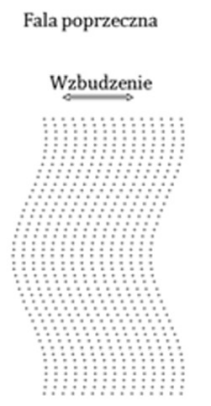

b)

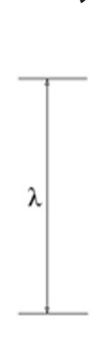

d)

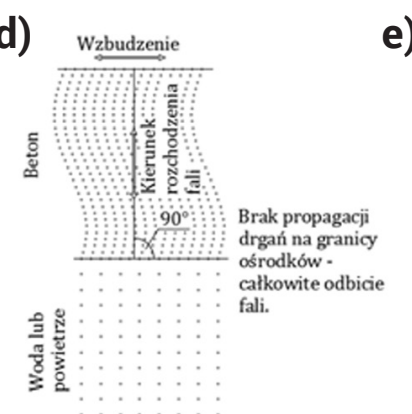

Fala podłużna
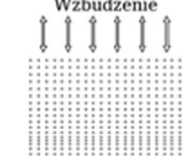

c)

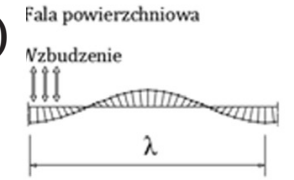

Rys. 2. Rodzaje fal występujące w ośrodkach stałych: a) fala poprzeczna, b) fala podłużna, c) fala powierzchniowa. d) fala poprzeczna na granicy ośrodków beton-woda lub powietrze, e) fala podłużna na granicy ośrodków beton-woda lub powietrze

Fig. 2. Types of waves occurring in solid mediums: a) longitudional wave, b) sheare wave, c) surface wave, d) longitudional wave between concrete and water or air, e) sheare wave between concrete and water or air

Kiedy fala poprzeczna propagująca w ośrodku stałym prostopadle do jego granicy (rys. 2d), napotka na granicy ośrodka płyn (np. woda, powietrze), nastąpi całkowite jej odbicie, ze względu na brak możliwości propagacji drgań w takiej postaci w ośrodkach ciekłych i gazowych [7]. W przypadku fali podłużnej, napotykającej na granicę ośrodków ciało stałe - płyn (rys. 2e), część energii zostanie przekazana cząsteczkom drugiego ośrodka, w postaci wzbudzenia fali podłużnej, a pozostała wartość pozostanie w ośrodku pierwotnym, w postaci fali wędrującej w kierunku odbicia. Intensywność odbicia fali będzie zależeć od wartości impedancji falowej ośrodków [8].

Zgodnie z powyższym, wzbudzając falę podłużną propagującą się przez ośrodek prostopadle do jego granicy otrzymuje się inną intensywność odbicia fali, w zależności, czy po przeciwnej stronie znajduje się woda, czy też powietrze. Nie otrzymuje się takiego rozróżnienia dla analogicznej fali poprzecznej.

W przypadku propagacji fali poprzecznej w ośrodku sta- łym pod kątem do jego granicy nastąpi odbicie, którego intensywność zależeć będzie od kąta, pod jakim pada fala, oraz od wartości impedancji falowej ośrodków. Na tej podstawie teoretycznie możliwym jest określenie, czy na granicy ośrodka fala poprzeczna napotkała na wodę, czy też na powietrze.

\section{Model numeryczny}

W celu sprawdzenia możliwości lokalizacji miejsca na granicy ośrodków o rożnej gęstości umieszonych w elemencie betonowym dostępnym z jednej strony za pomocą fali poprzecznej, wykonana została analiza MES w programie ABAQUS. W tym celu opracowano model numeryczny elementu, którego fragment pokazano i zaznaczono kolorem niebieskim na rysunku 3a. Proces propagacji fal mechanicznych zasymulowano za pomocą metody jawnej całkowania równań ruchu (dynamic explicit). Obliczenia zostały wykonane w dwóch wariantach. W pierwszym wariancie dla fragmentu walca reprezentującego wypełnienie rury (rys. 3b,c), nadano parametry materiałowe wody, w drugim parametry materiałowe powietrza. Dla tak wykonanych obliczeń porównano wykresy przemieszczenia w czasie punktu umieszczonego na górnej powierzchni elementu próbnego (rys. 4). Można na nim zobaczyć, że do momentu, w którym drgania propagują wzdłuż ścieżki pokazanej na rysunku 3c, wykresy są zbieżne (okres od 0 do 0,0002 s), natomiast od momentu dotarcia fali odbitej od granicy ośrodka (do którego przylega woda lub powietrze), do odbiornika (okres od 0,0002 do 0,0004 s), wykresy nie pokrywają się, co świadczy o innym stopniu odbicia fali w zależności od przylegającego do ośrodka medium (wody lub powietrza).

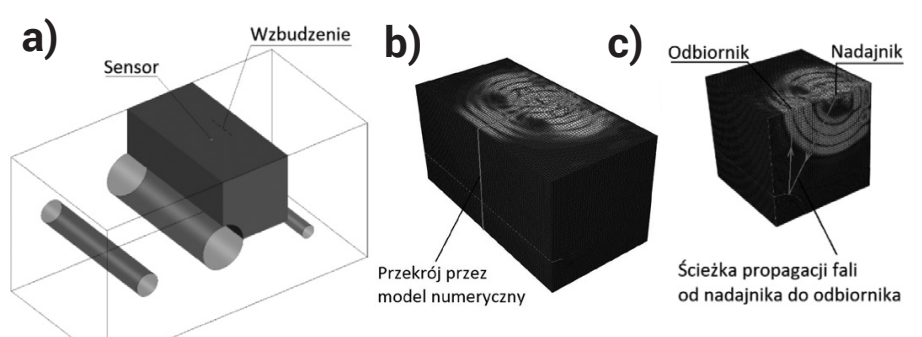

Rys. 3. Analiza numeryczna MES: a) widok zamodelowanego elementu próbnego, b) widok propagacji drgania na powierzchni analizowanego modelu numerycznego, c) przekrój przez model numeryczny pokazany na rysunku b) z obrazem propagacji fal oraz naniesioną ścieżką propagacji fali od nadajnika (wzbudzenie) do odbiornika (sensor)

Fig. 3. Numerical analysis in FEM: a) view of test piece, b) view the propagation of vibrations on the surface of the analyzed numerical model, c) section through the numerical model shown in Figure b) with the image of wave propagation and applied wave propagation path from the transmitter (excitation) to the receiver (sensor)

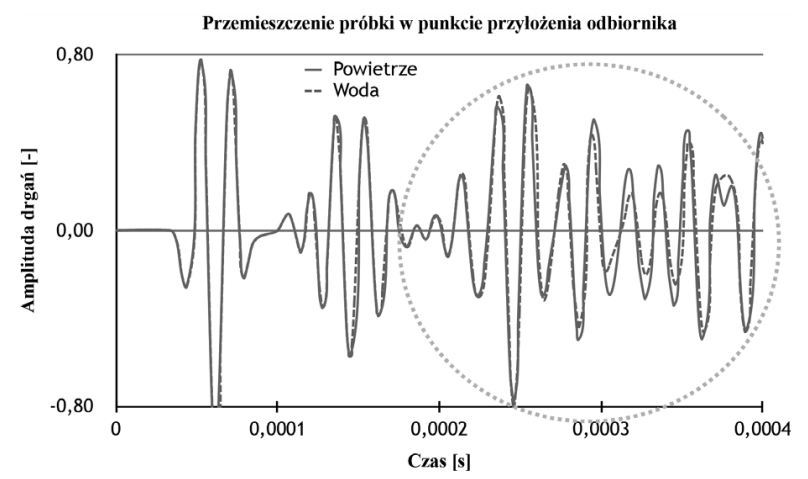

Rys. 4. Różnica w fali odbitej pomiędzy przewodem PCW wypełnionym wodą, a przewodem PCW wypełnionym powietrzem

Fig. 4. The difference in the reflected wave between the PVC pipe filled with water, and air-filled PVC pipe 


\section{Badania laboratoryjne}

W celu potwierdzenia możliwości lokalizacji miejsca na granicy ośrodków o różnej gęstości umieszonych w elemencie betonowym dostępnym jednostronnie, wykonane zostały badania nieniszczące z wykorzystaniem tomografu ultradźwiękowego. Widok tomografu pokazano na rysunku 5, za [3,7].

a)
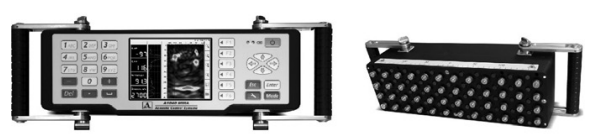

Rys. 5. Widok tomografu ultradźwiękowego: a) widok głowicy pomiarowej, b) sposób działania tomografu

Fig. 5. Ultrasonic tomography: a) view of device b) the method of operation

Badania zostały przeprowadzone na elemencie betonowym o wymiarach 500 x $500 \times 1000$ mm, który posiadał wtrącenia w postaci trzech przewodów PCW o średnicy kolejno 80,155 oraz $458 \mathrm{~mm}$ (rys. 6a). Na górnej powierzchni elementu naniesiona została siatka pomiarowa o wymiarach 100 x 100 mm (rys. 6a). W pierwszej kolejności wykonano badanie tomografem ultradźwiękowym lokalizacji przewo-
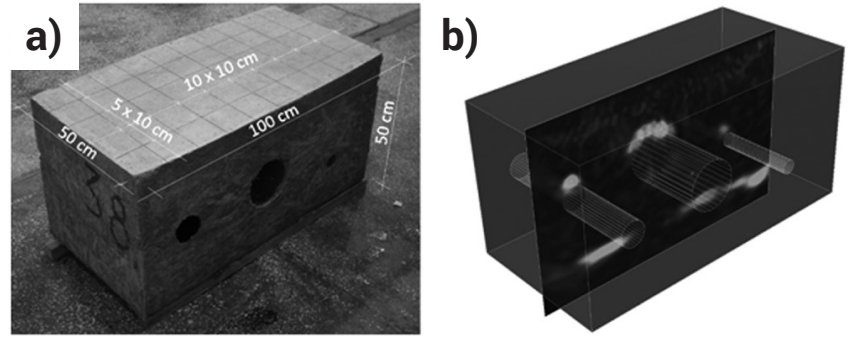

Rys. 6. Element betonowy wykorzystany do badań (a) wraz z jego ultradźwiękowym obrazem tomograficznym 3D (b)

Fig. 6. a) The concrete element used for testing b) tomographic image dów, korzystając z dostępu jedynie do górnej powierzchni elementu. Na tej podstawie powstał obraz tomograficzny pozwalający na lokalizację wtrąceń (rys. 6b).

Następnie wykonane zostały badania, których wynikiem są obrazy tomograficzne w trzech przekrojach przez środkowy przewód, podczas jego wypełnienia zarówno wodą, jak i powietrzem. Otrzymane wyniki w postaci pojedynczych obrazów tomograficznych zestawiono na rysunku 7. Na każdym z przekrojów widoczne jest odbicie sygnału od górnej powierzchni granicy ośrodków. O intensywności odbicia występującego na powyższych obrazach tomograficznych świadczy rozległość oraz kolor reprezentującego granicę ośrodka pola. W każdym z przypadków otrzymano różnicę pomiędzy przewodem wypełnionym wodą, a przewodem wypełnionym powietrzem. Różnica nie jest duża, jednak dla każdego z przekrojów zauważalna.

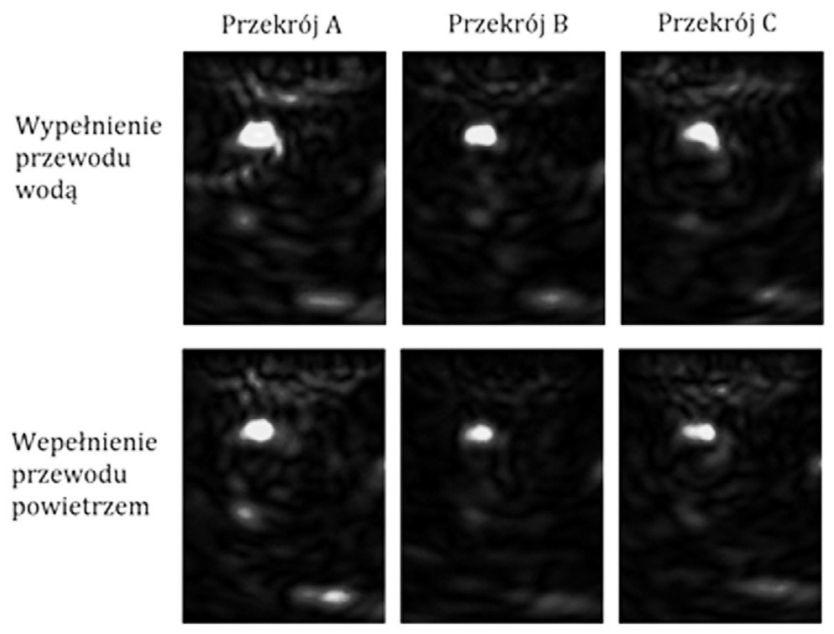

Rys. 7. Wyniki badań przeprowadzonych na elemencie betonowym z przewodem PCW wypełnionym wodą i powietrzem

Fig. 7. The results of the tests carried out on a sample of concrete with the pipe filled by water and air

\section{Podsumowanie}

W artykule przedstawiona została możliwość lokalizacji miejsca na granicy ośrodków o różnej gęstości umieszczonych w elemencie betonowym dostępnym jednostronnie, za pomocą tomografu ultradźwiękowego. Przedstawiono podstawy teoretyczne zjawiska propagacji fal ultradźwiękowych, wykonano symulację w programie MES, w wyniku której stwierdzona została możliwość lokalizacji miejsca na granicy ośrodków za pomocą tomografu ultradźwiękowego wykorzystującego fale poprzeczne. Następnie wykonano badania tomografem elementu betonowego, które wykazały zbieżność z symulacją komputerową. W obu przypadkach potwierdzono możliwość lokalizacji miejsca na granicy ośrodków umieszczonych w elemencie betonowym dostępnym jednostronnie za pomocą tomografu ultradźwiękowego i potwierdzono prawidłowość opracowanego modelu numerycznego.

Obliczenia wykonano przy użyciu zasobów udostępnionych przez Wrocławskie Centrum Sieciowo-Superkomputerowe (http://wcss.pl), grant obliczeniowy nr 300.

\section{Literatura}

[1] J. Hoła, K. Schabowicz, „State-of-the-art non-destructive methods for diagnostic testing of building structures - anticipated development trends", Arch. Civ. Mech. Eng., t. 10, nr 3, ss. 5-18, 2010.

[2] K. Schabowicz, "Ultrasonic tomography - The latest nondestructive technique for testing concrete members - Description, test methodology, application example", Arch. Civ. Mech. Eng., t. 14, nr 2, ss. 295-303, Luty 2014.

[3] K. Schabowicz i V. A. Suvorov, „Nondestructive testing of a bottom surface and construction of its profile by ultrasonic tomography", Russ. J. Nondestruct. Test., t. 50, nr 2, ss. 109-119, luty 2014.

[4] A. O. De La Haza, A. A. Samokrutov, i P. A. Samokrutov, „Assessment of concrete structures using the Mira and Eyecon ultrasonic shear wave devices and the SAFT-C image reconstruction technique", Constr. Build. Mater., t. 38, ss. 1276-1291, Stycze 2013.
[5] A. J. Chorin i A. J. Majda, Red., Wave Motion: Theory, Modelling, and Computation, t. 7. New York, NY: Springer US, 1987.

[6] L. Lam i H. C. Morris, Red., Wave Phenomena. New York, NY: Springer New York, 1989.

[7] Wave Physics. Berlin, Heidelberg: Springer Berlin Heidelberg, 2009.

[8] J. Krautkrämer, H. Krautkrämer, Ultrasonic Testing of Materials. Berlin, Heidelberg: Springer Berlin Heidelberg, 1983. 